\title{
Clayey soil stabilization using geopolymer and Portland cement
}

\author{
Pooria Ghadir ${ }^{1}$, Navid Ranjbar ${ }^{2, *}$ \\ ${ }^{I}$ Department of Civil Engineering, Iran University of Science and Technology, Tehran, Iran \\ ${ }^{2}$ Advanced and Innovative Materials (AIM) Group, Department of Civil, Environmental and Geomatic \\ Engineering, University College London, London WC1E 6BT, UK
}

\begin{abstract}
This study compares the mechanical performance of clayey soil stabilization using volcanic ash (VA) based geopolymer and ordinary Portland cement (OPC). The effects of curing conditions and time, alkali activator/clay and alkali activator molarity, and VA/clay ratio are determined. The compressive strength of the untreated clayey soil specimens could be increased from 0.2 to $4 \mathrm{MPa}$ and 2 to $12 \mathrm{MPa}$ at the $\mathrm{OC}$ and $\mathrm{DC}$ conditions, respectively, when the soil partially replaced by 15 $\mathrm{wt} \%$ of the binders. It is observed that geopolymer treatment is more efficient at the dry conditions (DC) while the Portland cement is superb at the wet environments (OC). This difference is associated with the role of water and $\mathrm{pH}$ in the kinetics of geopolymerization and the Portland cement hydration. Moreover, increasing the molarity of alkali activator and alkali activator/clay improve the compressive strength of the geopolymer treated soil. Besides, the higher energy absorption in all geopolymer specimens shows the superior ductility of this material in comparison with OPC.
\end{abstract}

Keywords: Soil stabilization; Geopolymer; Cement; Volcanic ash; Clay; Natural pozzolan.

*Corresponding author. E-mail addresses: n.ranjbar@ucl.ac.uk and navid0ranjbar@gmail.com 


\section{Introduction}

Lack of consideration for building and infrastructure construction on weak or soft soils is highly risky due to their poor shear strength and high compressibility. These make them susceptible to differential settlements. Therefore, it is important to enhance the soil properties using stabilization techniques that can respond to increasingly demanding situations.

Currently, chemical stabilization of soft soils is a common method by which binders, such as ordinary Portland cement (OPC) and lime are incorporated into the soil to improve particle interfacial bonds [1]. In geotechnical engineering projects, OPC is the most favored material because of sufficient mechanical properties, availability and cost. Therefore, it is used in numerous stabilization techniques such as deep cement mixing and grouting [2, $\underline{3}]$. However, the overdependence on cement has given rise to several environmental concerns, including large $\mathrm{CO}_{2}$ emission, natural resource depletion and dust generation. The OPC production is an extremely energy consuming process $(5000 \mathrm{MJ} / \mathrm{t} \mathrm{PC})$ which causes a $\mathrm{CO}_{2}$ emission of about $0.7-1.1$ tonne per tonne of OPC [4-6]. Apart from the environmental drawbacks, OPC often shows a high plastic shrinkage and a reduction of mechanical strength due to the loss of water and incomplete hydration at early ages [7]. This is a big drawback for geotechnical applications, especially in torrid zones, as wet-curing of a big site is not applicable.

In order to reduce the environmental impacts and enhance the mechanical performance, OPC is partially replaced with pozzolanic materials such as fly ash (FA), ground granulated blast furnace slag (GGBS), palm oil fuel ash (POFA), volcanic ash (VA) and red gypsum [1, $\underline{8}]$. The partially replaced OPC examples exhibited enhanced mechanical properties, and durability in terms of moisture resistance, water sorptivity and shrinkage $[\underline{8}, \underline{9}$. However, the pozzolanic replacement is often limited to low quantities and the environmental impacts of OPC is still a concern. 
Several attempts have been conducted to active the pozzolanic wastes to produce a binder with a similar property as OPC gel. $\mathrm{Na}_{2} \mathrm{CO}_{3}$ was effectively used to active GGBS to produce binder [10]. While, a similar result was not observed in another experiment [11]. This contradictory was attributed to the different $\mathrm{pH}$ environment of the experiments. The $\mathrm{Na}_{2} \mathrm{CO}_{3}$ hardly created a high $\mathrm{pH}$ environment in the clay-water-GGBS system while the rate of activating reactions depended on the $\mathrm{pH}$ of the starting solution [12]. Carbide slag, which is mainly composed of $\mathrm{Ca}(\mathrm{OH})_{2}$, was used to activate the GGBS to form a binder, however high water content used in that matrix had a significant impact on the early-age strength development [11].

Geopolymer has been emerging as a potential alternative to Portland cement by converting industrial aluminosilicate rich wastes into a value added binder [13, 14]. Apart from the environmental aspects geopolymer stabilized soils have been shown superior properties to meet the requirements engineered clayey soil through compact microstructures, improved mechanical properties and volume stability [15-18]. Different mixing designation have been investigated mechanical performance of geopolymer stabilized clayey soils. It was observed that shrinkage strain of metakaolin-geopolymer stabilized soil is much lower than those of the unstabilized or OPC incorporated ones. This low shrinkage was attributed to the slow evaporation of pore water from the compact structure of the stabilized soil using geopolymer [17]. Also, the compressive strength of lightweight GGBS-geopolymer stabilized clayey soil was improved by 200 to $350 \%$ compared to its corresponding lightweight OPC specimens [19]. Similarly, for the same percentage of binder content, the GGBS-geopolymer stabilized soil indicated 600\% mechanical strength improvement compared to the OPC treated specimens over short-term curing time of 28 days [15]. However, FA-geopolymers often show a slower and long-lasting strength development compare with those of OPC at low curing temperatures. A comparison between FA-soil mixtures with and without 
alkaline activator showed a remarkable increase in strength of alkali activated specimens from 0.3 to $2.8 \mathrm{MPa}$ at 28 days and 5.2 $\mathrm{MPa}$ after 90 days [20]. Likewise, it was observed that with comparable $28^{\text {th }}$ day mechanical properties, strength development of FA-geopolymer stabilized samples were in the range of $250-500 \%$ after one year, while it was limited to $10-25 \%$ in OPC specimens [21]. However, a higher early strength was observed when FA-geopolymer soil was cured at higher temperatures $[22, \underline{23}]$. The compressive strength of POFA-geopolymer soil which subjected to hot curing was increased by $112 \%$ in comparison with that of cured in the absence of the heating process [24].

In addition to the effects of curing condition and time, it was reported that increasing the binder to soil ratio improves the compressive strength of stabilized soils [22, 25]. Also, increasing the sodium silicate/sodium hydroxide ratio or higher alkali activator concentration increase the mechanical strength of the geopolymer soil treated specimens however they reduce the workability $[21, \underline{26}]$. In contrary, an increase in strength was reported by decreasing activator/ash ratio. When the $\mathrm{Na}_{2} \mathrm{O} / \mathrm{fly}$ ash ratio increased from 0.160 to 0.375 , the mechanical strength decreased by $50 \%$ [21]. The variation in results are due to the type of mixture, curing time and condition of geopolymers. Therefore, further studies on the controlling variables are required.

This study compares the mechanical performance of clayey soil stabilized with VA-geopolymer and OPC and investigates the dominant factors of stabilization process, including: curing conditions, curing time and binder content. The incorporation of both VA and OPC replacement contents varied in the applicable range of 0 to 15 w.t.\% of the soil. Furthermore, the geopolymer stabilization was optimized by considering the alkali concentration and binder to soil ratio. The experiment carried out at two curing conditions of oven dried and optimum water content to verify stabilizer function at different climates. 


\section{Materials and methods}

\subsection{Soil characterization}

A locally low plastic available clayey soil was collected from Shiraz-Iran. It contained a trace of sand and fine gravel. Therefore, it was dried and sieved through No. 4 (opening of $4.75 \mathrm{~mm}$ ) to remove the gravel fraction. The full particle size analysis of the soil used in this study can be observed in Fig. 1. The engineering properties of studied soil in terms of the Atterberg limits, grain fractions, and soil classification was according to the ASTM D 4318, the ASTM D 422 and the Unified Soil Classification System, respectively, as in Table 1. The grain size distribution was obtained by means of sieve analysis coupled with hydrometer testing as per ASTM D 2487.

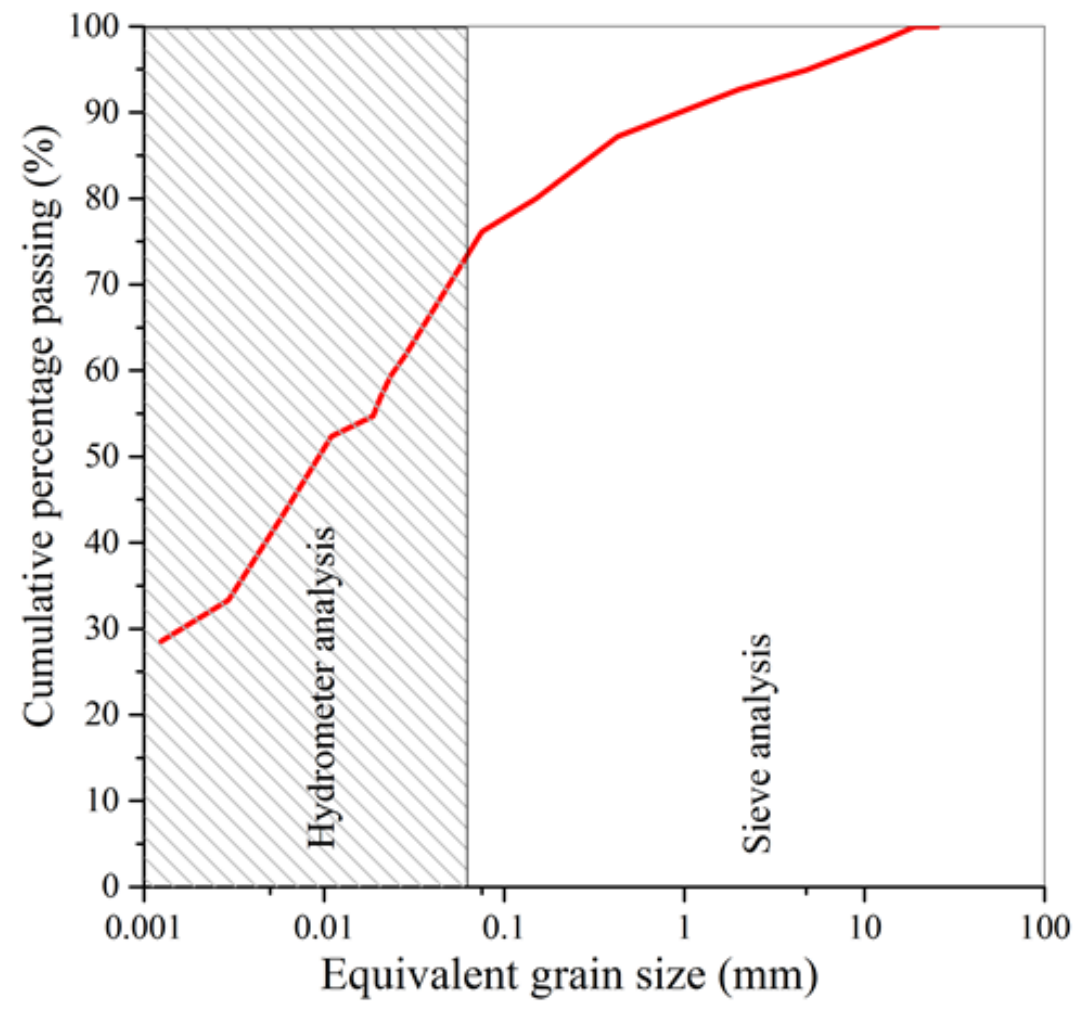

Fig 1. Particle size distribution of the Shiraz clayey soil.

Table 1. Engineering properties of clay soil. 


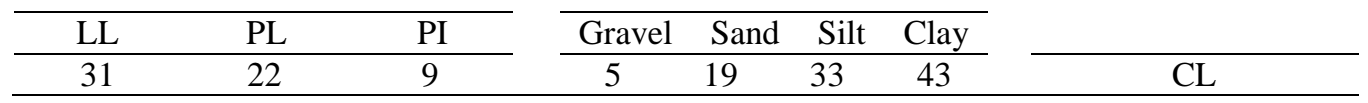

To determine the maximum dry density $\left(\rho_{\max }\right)$ and the optimum water content (OWC) of the soil the standard Proctor compaction test was conducted based on the ASTM D 698. The $\rho_{\max }$ of 1.74 $\mathrm{g} / \mathrm{cm}^{3}$ and OWC of $14 \%$ of untreated soil were determined for the stabilized specimens.

\subsection{Binders characterization}

The volcanic ash used in this research was collected from the Taftan Mountain, located in the south east of Iran. The as-received material was sieved to $74 \mu \mathrm{m}$ to remove large particles and impurities. The ordinary Portland cement (OPC) type II was collected from Fars Cement Company. The X-ray fluorescence (XRF) using PANalytical Axios mAX instrument was used to determine the oxide composition of the VA and OPC, as listed in Table 2.

Table 2. Chemical composition of VA and OPC.

\begin{tabular}{lllllllllllll}
\hline Oxide composition & $\mathrm{SiO}_{2}$ & $\mathrm{CaO}$ & $\mathrm{Al}_{2} \mathrm{O}_{3}$ & $\mathrm{Fe}_{2} \mathrm{O}_{3}$ & $\mathrm{~K}_{2} \mathrm{O}$ & $\mathrm{Na}_{2} \mathrm{O}$ & $\mathrm{MgO}$ & $\mathrm{TiO}_{2}$ & $\mathrm{SrO}$ & $\mathrm{SO}_{3}$ & $\mathrm{P}_{2} \mathrm{O}_{5}$ & $\mathrm{MnO}$ \\
\hline VA [wt.\%] & 46.8 & 19.1 & 13.5 & 8.5 & 4.3 & 4.1 & 1.7 & 0.9 & 0.3 & 0.3 & 0.2 & 0.2 \\
OPC [wt.\%] & 11.78 & 69.62 & 3.23 & 8.425 & 1.45 & 0.36 & 2.36 & 0.295 & 0.121 & 1.92 & 0.049 & 0.168 \\
\hline
\end{tabular}

Specific surface area of VA and OPC as measured by nitrogen adsorption according to the Brunauer, Emmett, and Teller (BET) method using NanoSORD92 instrument were 2.424 and 2.003 $\mathrm{m}^{2} / \mathrm{g}$, respectively.

In order to evaluate the efficiency of geopolymer and cement on stabilization of clayey soil, three sets of predetermined concentrations of VA or cement were mixed with the activator for a constant time of 5 min. Sodium hydroxide solution and water were used as activators for the VA and OPC, respectively. Set 1 was determined to compare the different soil replacement by the VA or OPC in the range of $0,5,10,15$ w.t.\%. The activator content was kept 14 w.t.\% (as in the optimum water content of the untreated soil) for all the specimens. Sets 2 and 3 were performed only for 
geopolymer treated soil. Set 2 was to investigate the effect of alkali activator molarity at 4, 8 and $12 \mathrm{M}$, while the VA replacement kept at 10 w.t.\%. Set 3 focused on the influence of alkali activator/optimum water content which varied by $1,1.2$ and 1.4; and, the binder replacement and sodium hydroxide molarity kept constant at 15 w.t.\% and $8 \mathrm{M}$.

\section{Soil stabilization and characterization tests}

\subsection{Specimen preparation and mechanical characterization}

The unconfined-uniaxial compressive test specimens were prepared using cylindrical molds with an inner diameter of $32 \mathrm{~mm}$ and a height/diameter ratio of 2.0. The soil was manually mixed with either geopolymer or cement solution for ten minutes to achieve a homogeneous mixture. The soil liquid fraction ratio was kept constant, $14 \%$, to the optimum water content of the untreated sample. All samples were statically compacted in three equal layers with the aid of loading machine and extruded using a Harvard Miniature Compaction Apparatus once after the compaction. The specimens were cured at two conditions of optimum water content (OC) and dry (DC) and tested after $1^{\text {st }}, 7^{\text {th }}$, and $28^{\text {th }}$ day. The average of three samples tested for all the measurements. The specimens wrapped using plastic film and cured in plastic chamber with a nearly constant relative humidity of $80 \pm 2 \%$ and temperature of $\sim 25 \pm 2{ }^{\circ} \mathrm{C}$ using humidifier for OC condition curing. After the course of curing, the samples were unwrapped and UCS testing was performed. The DC curing was carried out by placing the specimens in oven of $40^{\circ} \mathrm{C}$ and relative humidity of $15 \pm 2 \%$. Summary of the test plan is shown in table 3.

Table 3. Summary of the test schedule for the effects of geopolymer and OPC on soil stabilization.

\begin{tabular}{|c|c|c|c|c|c|c|c|}
\hline & $\begin{array}{l}\text { Binder } \\
\text { type }\end{array}$ & $\begin{array}{c}\text { Binder } \\
\text { replacement } \\
{[\%]} \\
\end{array}$ & $\begin{array}{c}\text { Activator } \\
\text { type }\end{array}$ & $\begin{array}{c}\text { Alkali activator } \\
\text { molarity } \\
{[\mathrm{M}]} \\
\end{array}$ & $\begin{array}{l}\text { curing } \\
\text { time } \\
\text { [day] }\end{array}$ & $\begin{array}{l}\text { curing } \\
\text { condition }\end{array}$ & $\begin{array}{c}\text { Activator } \\
\text { content/optimum } \\
\text { water content }\end{array}$ \\
\hline \multirow{2}{*}{ Set 1} & VA & $0,5,10,15$ & $\mathrm{NaOH}$ & 8 & $1,7,28$ & $\mathrm{OC}^{*}, \mathrm{DC}^{¥}$ & $1^{\hbar}$ \\
\hline & OPC & $0,5,10,15$ & $\mathrm{H}_{2} \mathrm{O}$ & - & $1,7,28$ & $\mathrm{OC}, \mathrm{DC}$ & 1 \\
\hline Set 2 & VA & 10 & $\mathrm{NaOH}$ & $4,8,12$ & 1,28 & OC,DC & 1 \\
\hline
\end{tabular}




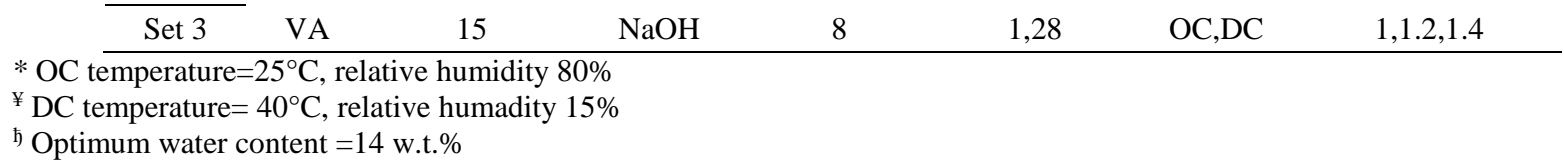

UCS testing was performed with a universal testing machine (Digital Tritest 50/ELE). The axial strain rate was controlled at a rate of $0.5 \mathrm{~mm} / \mathrm{min}$. The maximum strength and the stress-strain curves were obtained by the average of three specimens. Energy absorption of the specimens was determined as the area under compression stress-strain of each specimen [27].

The actual moisture content of all specimens was measured immediately after the compressive testing by heating them at $110{ }^{\circ} \mathrm{C}$ for $24 \mathrm{~h}$.

Optical images of treated and untreated samples were recorded by a Dino-Lite digital microscope (AM4113ZT(R4)) with magnification range of 10x 50x and 200x.

\subsection{Microstructural characterization}

Microstructural characterization was carried out 28 days cured specimens by Scanning Electron Microscopy (SEM), together with Energy Dispersive Spectroscopy (EDS) elemental analysis and X-ray diffraction (XRD). The SEM (TESCAN vega 3, Czech Republic) was operated in a high vacuum condition, at $20 \mathrm{kV}$ accelerating voltage in the mode of backscattered electron (BSE). EDS at $20 \mathrm{KV}$ fully embedded into the TESCAN system was used, to determine the elemental analysis

of the specimens. The XRD patterns were measured on an DRON-8 (BOUREVESTNIK company, Russia) using $\mathrm{Cu} \mathrm{K} \alpha$ radiation ( $\lambda=1.54056 \AA)$, operated at $40 \mathrm{kV}$ and $30 \mathrm{~mA}$ with a step size of $0.04 \mathrm{deg}$ and a scanning rate of $0.15 \mathrm{deg} \mathrm{s}^{-1}$ in the $2 \theta$ range of 5 to $80 \mathrm{deg}$.

\section{3. pH of soil}


The $\mathrm{pH}$ values were measured by using a $\mathrm{pH}$ Meter and Probe, according to the ASTM D 4972. The samples were prepared by crushing and sieving of $10 \mathrm{~g}$ of soil specimens through a $2.0 \mathrm{~mm}$ (No. 10) sieve and mixing with $10 \mathrm{ml}$ of water for $5 \mathrm{~min}$. The samples were then stored in a curing room. The $\mathrm{pH}$ was recorded in one-hour duration.

\subsection{Reactivity test}

The reactive fraction of the VA was quantified by dissolving $1 \mathrm{~g}$ of ash in $100 \mathrm{~mL} \mathrm{NaOH}$ solution for 24 hours at a temperature of $40{ }^{\circ} \mathrm{C}$. The insoluble particles were separated from the solution using a centrifuge and washed with distilled water to a neutral $\mathrm{pH}$ and dried for 1 hour at $250^{\circ} \mathrm{C}$ and weighted [28].

\section{Results and analysis}

\subsection{Compressive strength}

Figure 2 and 3 compares the unconfined compressive strength and moisture content, respectively, for the geopolymer and OPC treated soil specimens which cured in different conditions of OC and DC at 1, 7 and 28 days. Independent of binder concentration, treatment of the soil specimens with either geopolymer or OPC increases the compressive strength of the specimen over time. However, the mechanical performance of the treatment methods is highly depends on humidity and temperature. The geopolymer treatment shows superb performance at the DC curing. This is attributed to the role of water and temperature on the geopolymerization. The structural water, what is essential and participates in geopolymerization, provides a medium for dissolution and hydrolysis of aluminosilicates and supplies ions transfer. The structural water is not evaporable at low temperatures [29, 30]. However, there is another water portion, the residual water, which is 
unfavorable for the strength development as it reduces the alkalinity of the matrix through dilution effects, and slows the rate of geopolymerization at dissolution and hydrolysis stages [24, $\underline{31}, \underline{32}]$. The residual water is only used to provide sufficient workability [13]. As observed, high-water content retards the strength development of geopolymer treated specimens at OC, Figure 2. Unlike at the DC curing, the free water is evaporated gradually and alkalinity of the mixture increased. On the other hand, the reactivity of VA is slow at low temperatures because the reaction is based on the dissolution of the particles which increases at higher temperatures [33]. Therefore, heat curing accelerates the dissolution, hydrolysis and polycondensation of the geopolymers during the early age. Unlike, in OPC reaction water is essential for the formation of C-S-H gel and completion of the reaction. Therefore, maintaining the specimen moisture results in a gradual strength development at OC, Figure 2. However, at dry condition the lack of sufficient water for the hydration causes a cessation on the reaction and suppresses the soil treatment. Noteworthy, the rise which observed in the strength of the OPC based specimens at DC is associated with the increase in soil strength itself due to the volumetric shrinkage that occurs during the air drying process which produces a denser soil structure $[34, \underline{35}]$. The compressive strength development of the geopolymer treated specimens is less changed once the moisture content of the specimens balanced at a constant level of $1 \%$, Figure 3 . The moisture content of the specimens is almost independent of material type but curing conditions.

Independent of binder types, the increase in the binder/clay improves the compressive strength of the matrix at the OC but not at DC. This difference is attributed to the constant activator content, 14 w.t. $\%$, and the rate of water evaporation. Increasing the rate of water evaporation accelerates the dissolution and hydrolysis of higher numbers of reactive particles while, slow down the further activation of partially reacted particles once the water is evaporated. However, activation of higher 
number of particles is possible at $\mathrm{OC}$ as there is enough water for further binder gel formation and therefore, higher compressive strength is achieved. A similar trend is observed at the energy absorption of the materials at DC. However, a reduction in energy absorption of 28 days cured OPC specimens at OC is associated with the brittle structure of OPC specimens over time, Figure 4.

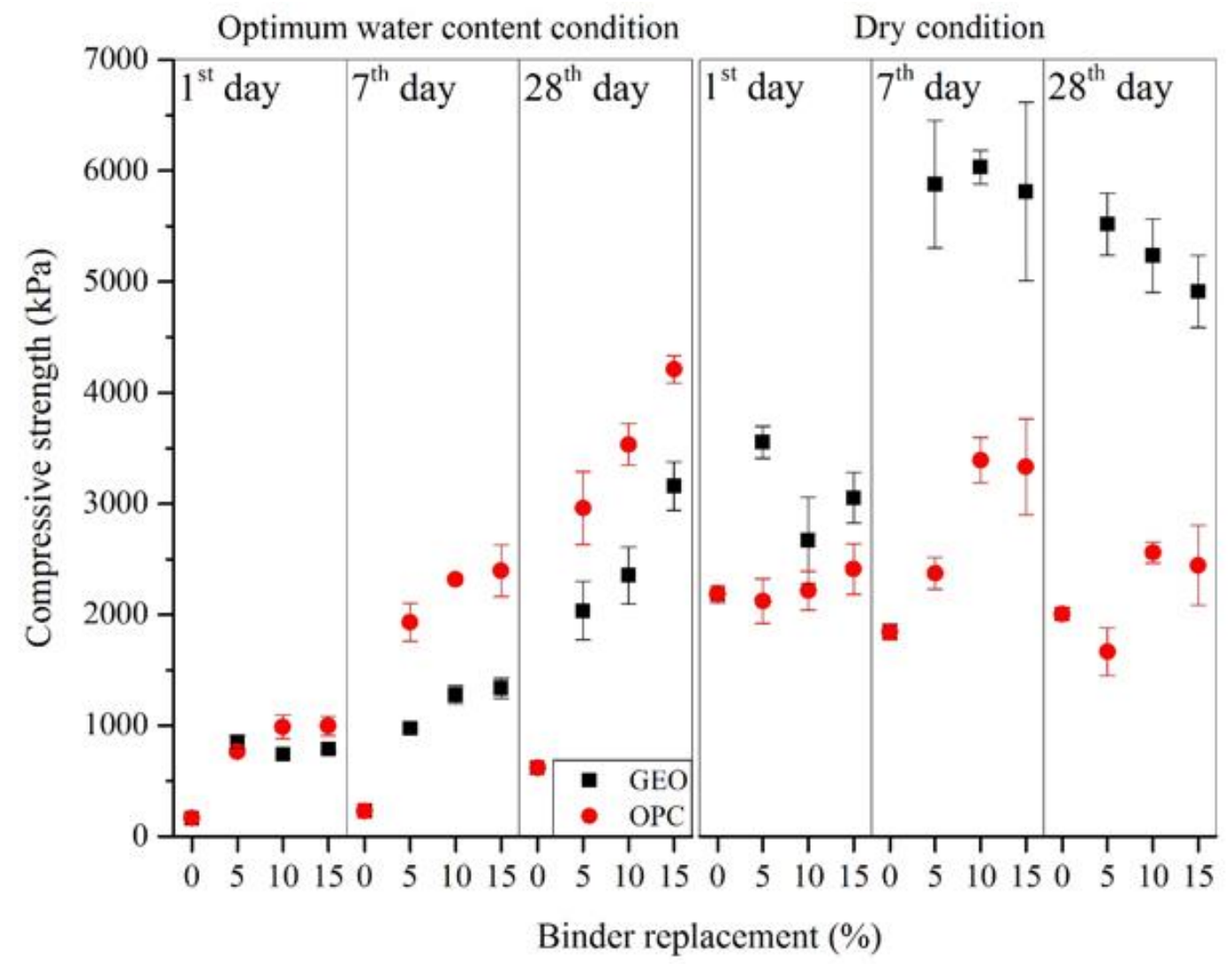

Fig 2. Compressive strength of stabilized soils using geopolymer and OPC at optimum water content and dry conditions with different binder content at different ages. 


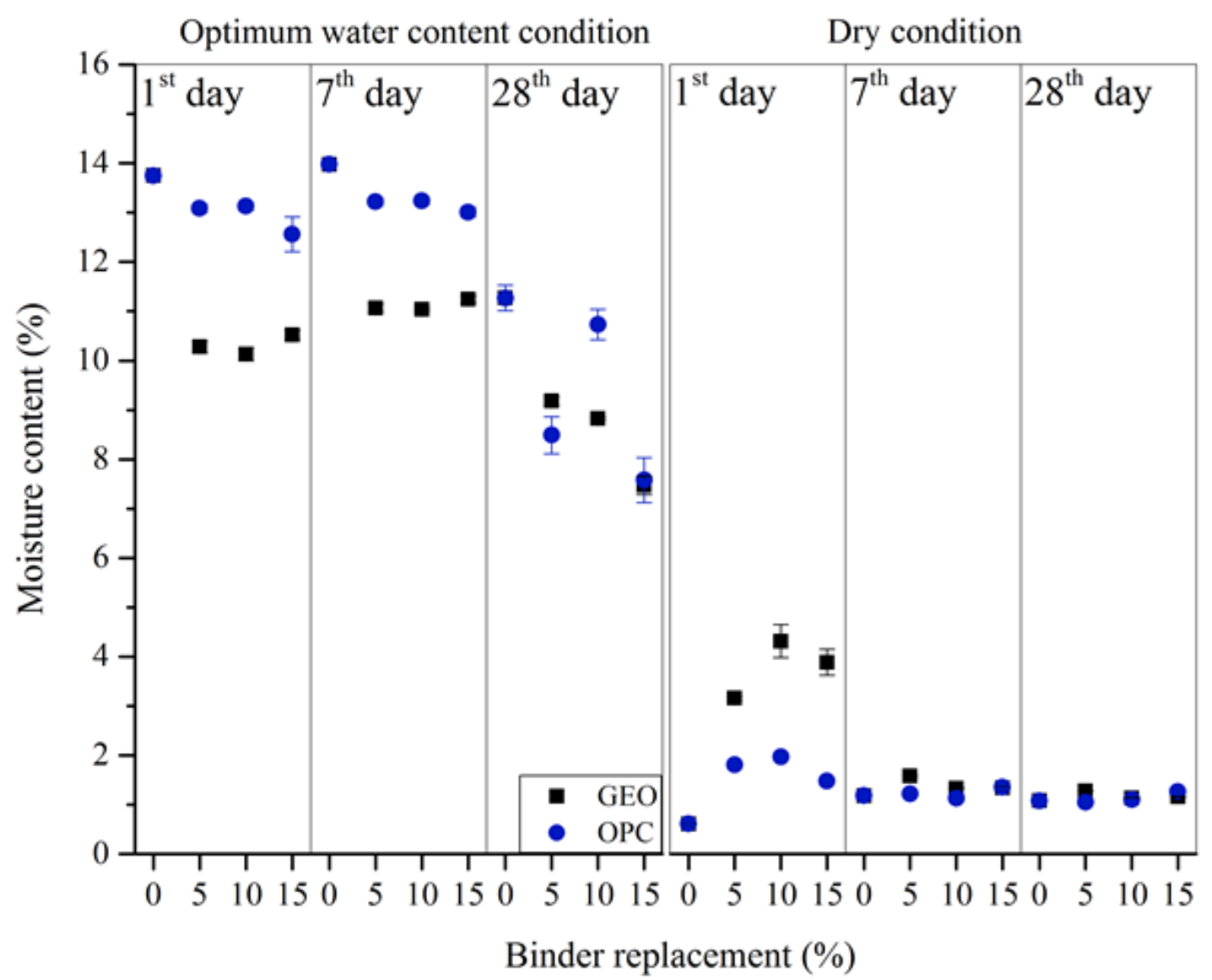

Fig 3. Moisture content of stabilized soils using geopolymer and OPC at optimum water content and dry conditions with different binder content at different ages. 


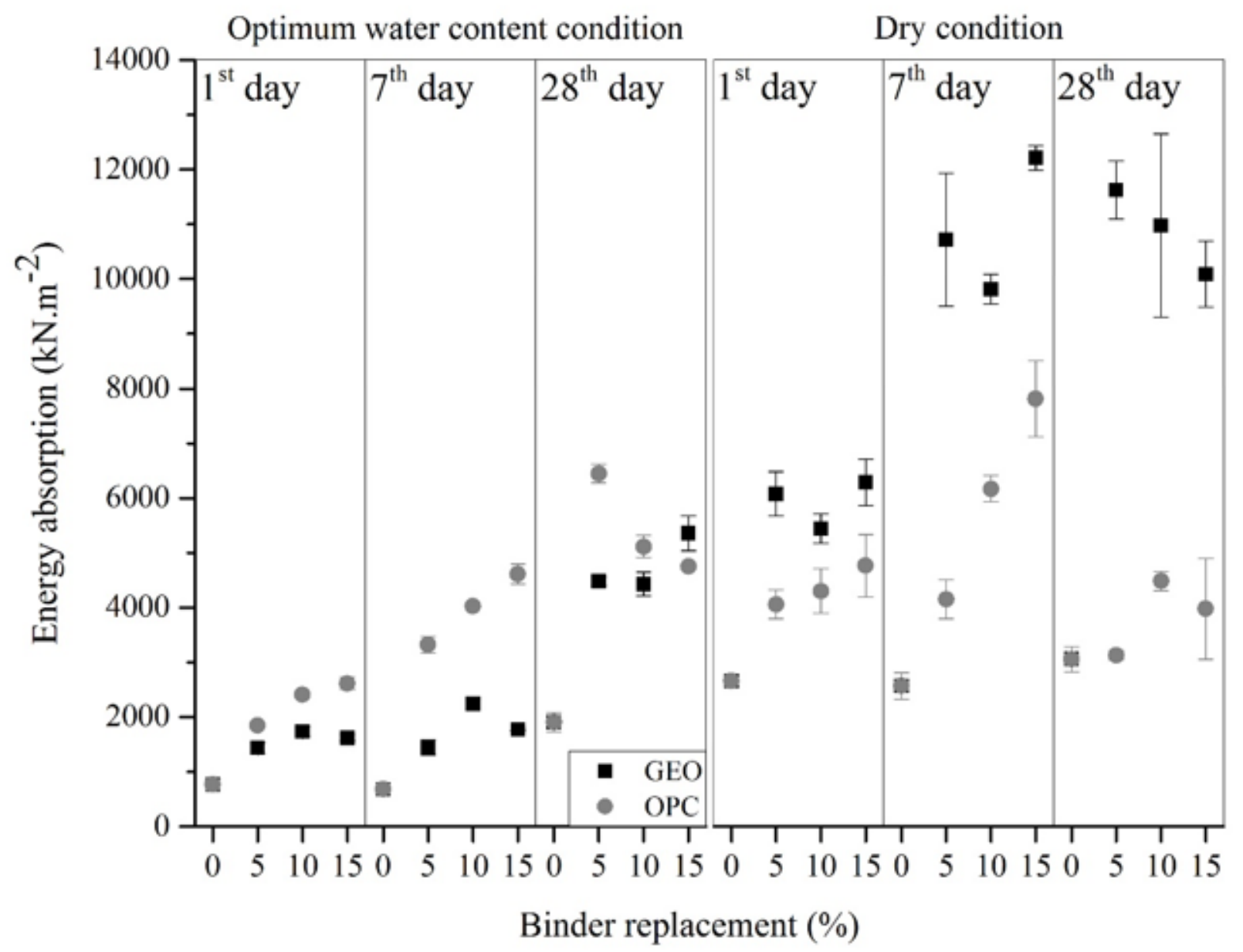

Fig 4. Energy absorption of stabilized soils using geopolymer and OPC at optimum water content and dry conditions with different binder content at different ages.

\subsection{XRD analysis}

The XRD patterns of untreated soil, stabilized soil using 15 w.t. $\%$ geopolymer and OPC at $28^{\text {th }}$ day of curing are shown in Figure 5. The main crystalline phases of the as received clayey soil are calcium carbonate and quartz [36]. Considering the small fraction of soil replacement with the binders, the aforementioned crystalline phases are still dominant in the treated soils. A trace of anorthite is observed in the geopolymer treated specimens which attributed to the crystalline structure of the VA and VA based geopolymer [37]. 


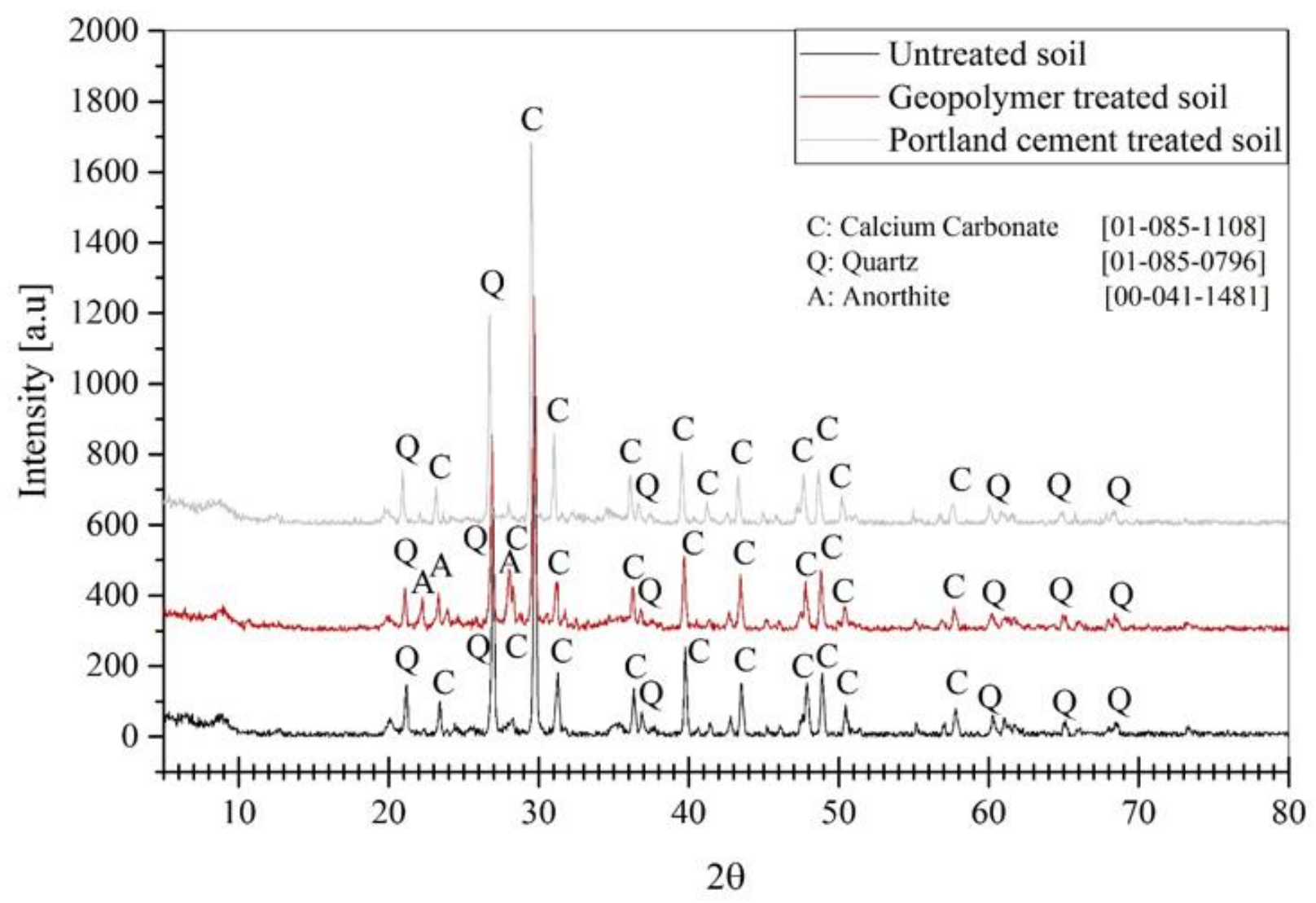

Fig 5. XRD patterns of clayey soil, geopolymer and Portland cement treated clayey soil specimens.

\subsection{SEM-EDS characterization}

Fig 6a-c and insets show optical images of untreated soil, stabilized soil using 15 w.t.\% geopolymer and OPC at $28^{\text {th }}$ day of curing. The insets, Figure 6d-f, shows the optical images of pure soil, VAgeopolymer and hydrated OPC. As observed in the Figure $6 \mathrm{~b}$ and $\mathrm{c}$ both materials, OPC and geopolymer, has been distributed uniformly through the soil particles. This is obtained by proper mixing of a diluted form of the activator with a low viscosity. Furthermore, the BSE images show a higher degree of compaction in the treated samples, particularly at geopolymer treated specimens. This is due to the high alkalinity of the binder which disconnects the soil particles and makes the 
rearrangement of the particles possible. Besides, the slippery binders lubricate the surface of particles to roll over each other during the compaction.
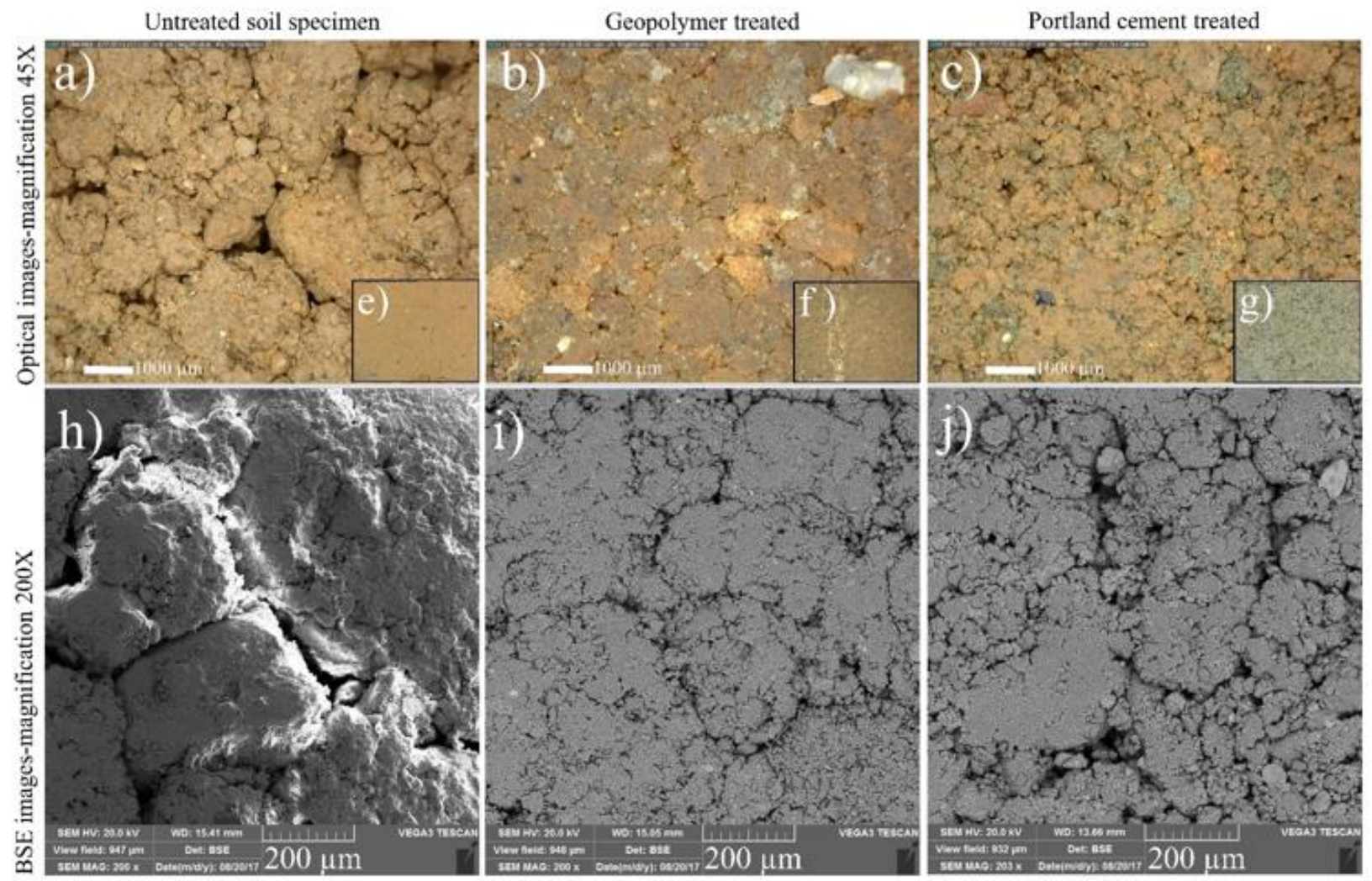

Figure 6. Optical and SEM images of a, e, h) untreated soil, b, f, i) stabilized soil using geopolymer (15\% replacement at dry condition), c, g, j) stabilized soil using OPC (15\% replacement at optimum water content condition) at $28^{\text {th }}$ day of curing.

Figure $7 \mathrm{a}$ and $\mathrm{b}$ shows the influences of alkali activator concentration on the compressive strength of geopolymer treated specimens. The increase in molarity of the sodium hydroxide from 4 to 12 $\mathrm{M}$ resulted in higher dissolution of aluminosilicate precursors and, therefore, a higher mechanical strength of the geopolymer specimens at both OC and DC. This is attributed to a higher reactivity of volcanic ash particles at higher alkalinities, Figure 7c [ $[38, \underline{39}]$. Previously, it was shown that the 
unreactive particles remain inert and should be considered in geopolymer mixing designation to overcome the overestimation of aluminosilicate performance [28, $\underline{40]}$.

The moisture variation of the specimens is shown in Figure 8. It is observed that change in molarity of $\mathrm{NaOH}$ solution almost doesn't influence on the final moisture content of the specimens. Depending on the curing condition the moisture content balanced to about 8.5 and $0.5 \%$ at $\mathrm{OC}$ and DC, respectively.

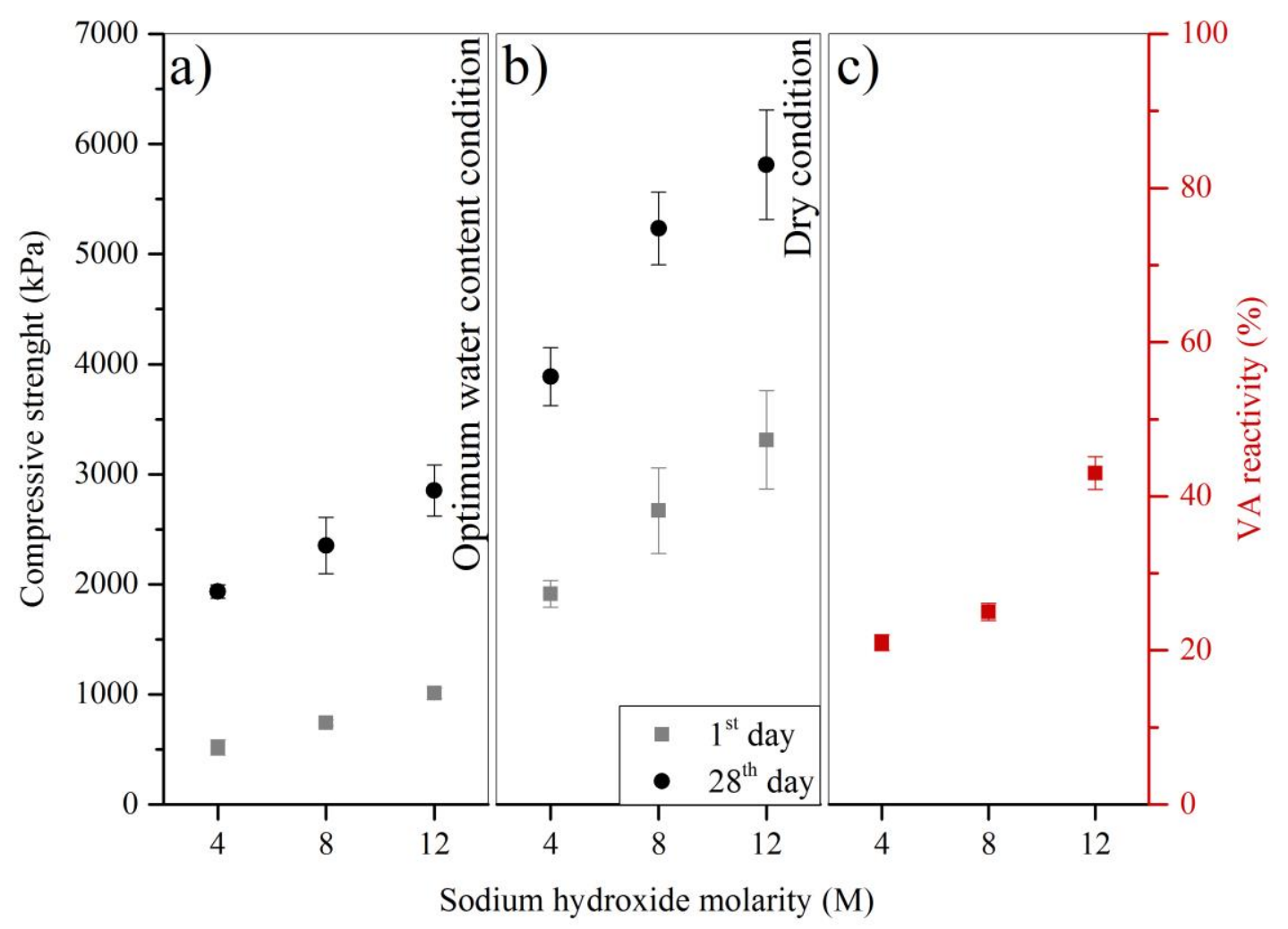

Fig 7. Compressive strength of stabilized soils using VA-geopolymer at a) OC and b) DC with different alkali activator molarity at different ages, c) VA reactivity at different alkali activator molarity. 


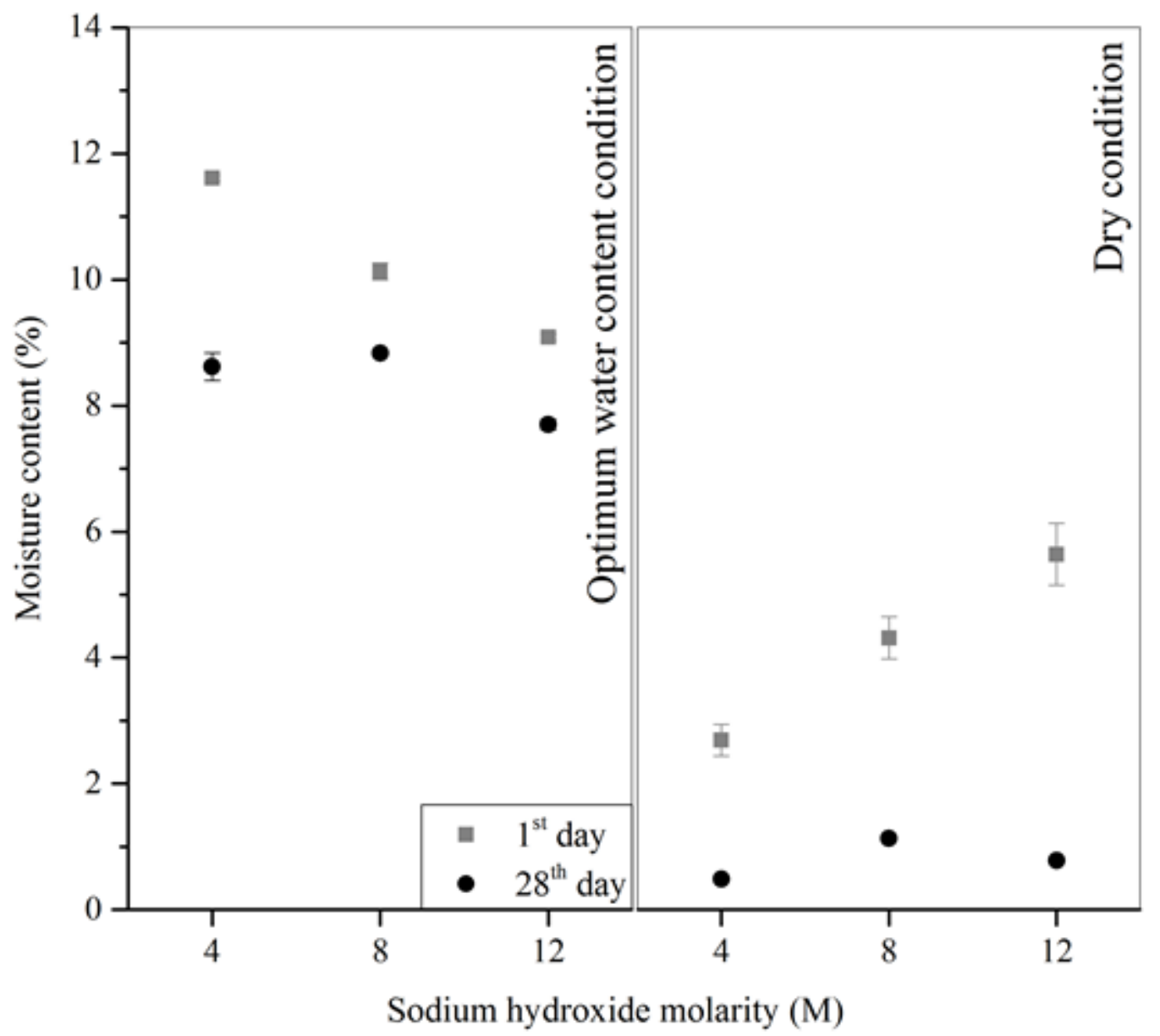

Fig 8. Moisture content of stabilized soils using geopolymer at OC and DC with different alkali activator molarity at different ages.

Figure 9 shows the compressive strength of the set 3 where the alkali activator to optimum water content ratio was changed in 1,1.2 and 1.4. At the DC curing, the increase in alkali activator content from 1 to 1.4 resulted in 1.7 and 2.3 times rise in compressive strength of the treated soil at $1^{\text {st }}$ and $28^{\text {th }}$ day, respectively. This mechanical improvement is due to the activation of more particle through the higher alkali activator concentration in the matrix [41]. Despite of great efficiency at DC curing, the increase in alkali activator was ineffective at the OC, Figure 10. This is due to the dilution of alkali activator at the wet condition. As observed, the increase in alkali activator rises 
the moisture content in early and long-term curing at $\mathrm{OC}$, while it reduces to about $1 \%$ in DC curing at $28^{\text {th }}$ day.

Figure 11 shows the energy absorption of the set 2 and set 3 where the alkali activator concentration and the alkali activator/optimum water content of the geopolymer treated soil specimens are investigated. Similar to the trends of compressive strength, increasing the alkali activator/clay had more influence on the energy absorption compared with the increase in molarity of the solution. However, higher energy absorption in all the geopolymer specimens shows the more ductility of this material compare with OPC. A similar conclusion was derived by comparison of flexural performance of reinforced geopolymer and OPC concrete beams [42].

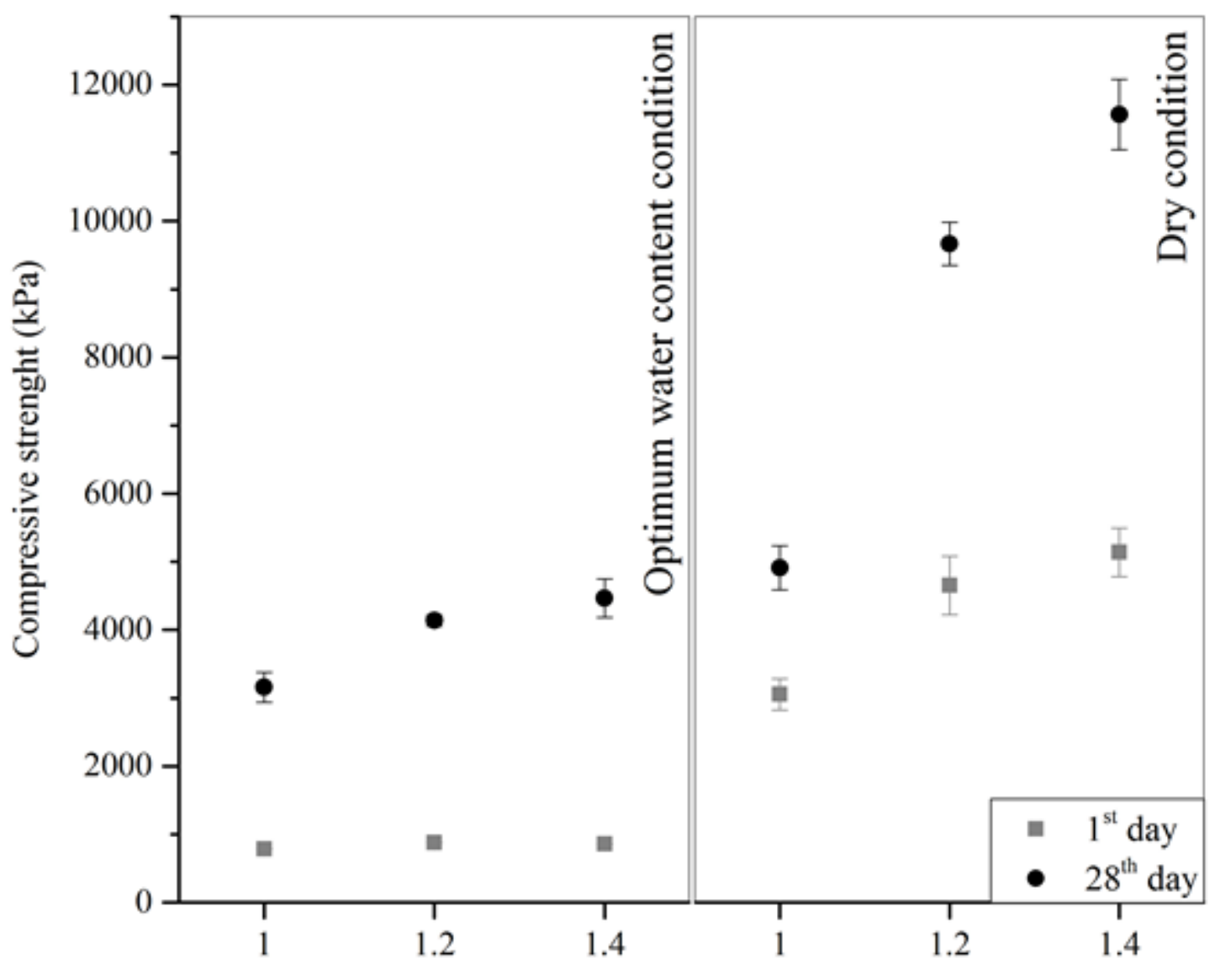

Alkali activator content / Optimum water content 
Fig 9. Compressive strength of stabilized soils using geopolymer at optimum water content and dry conditions with different alkali activator content at different ages.

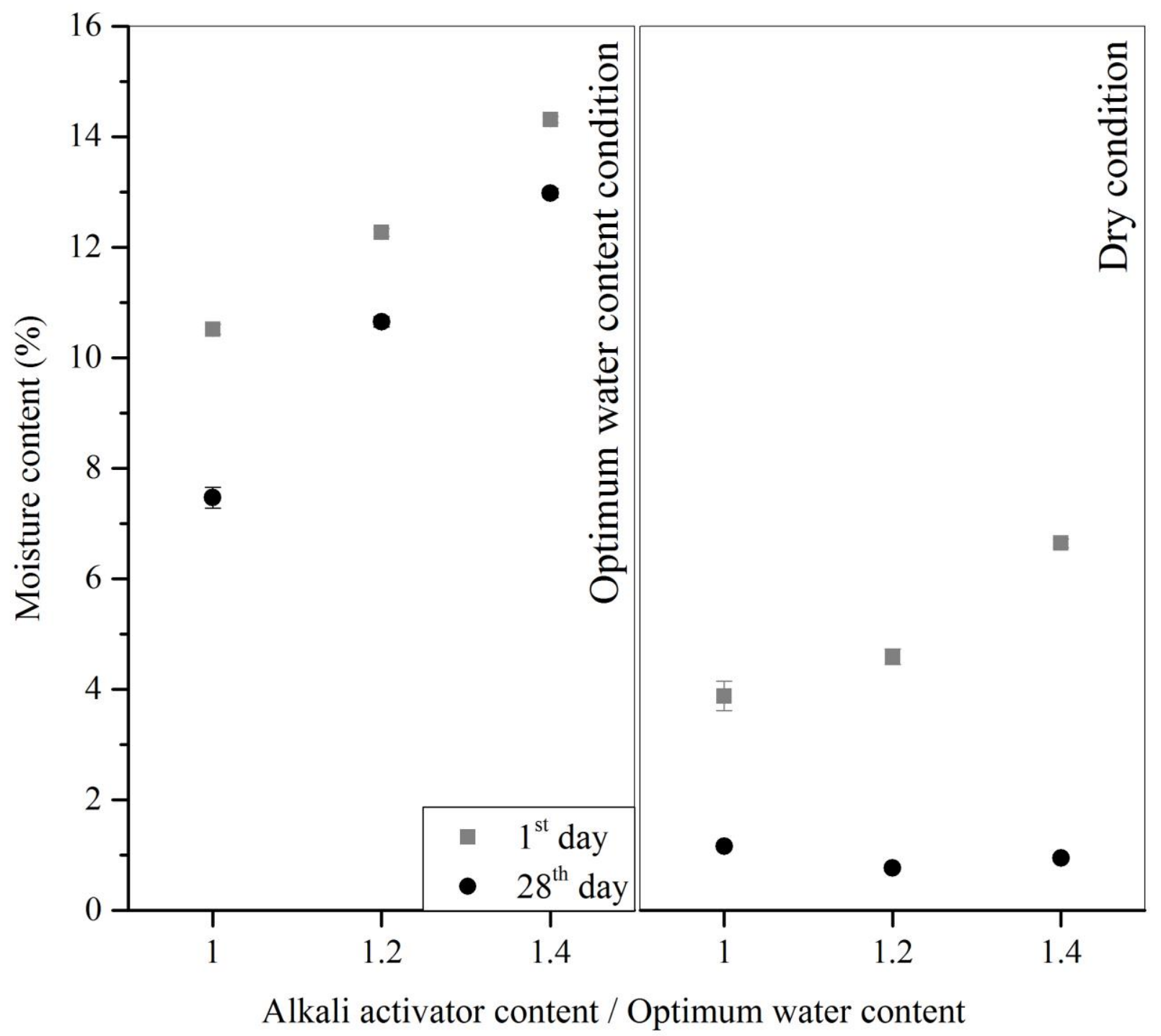

Fig 10. Moisture content of stabilized soils using geopolymer at optimum water content and dry conditions with different alkali activator content at different ages. 


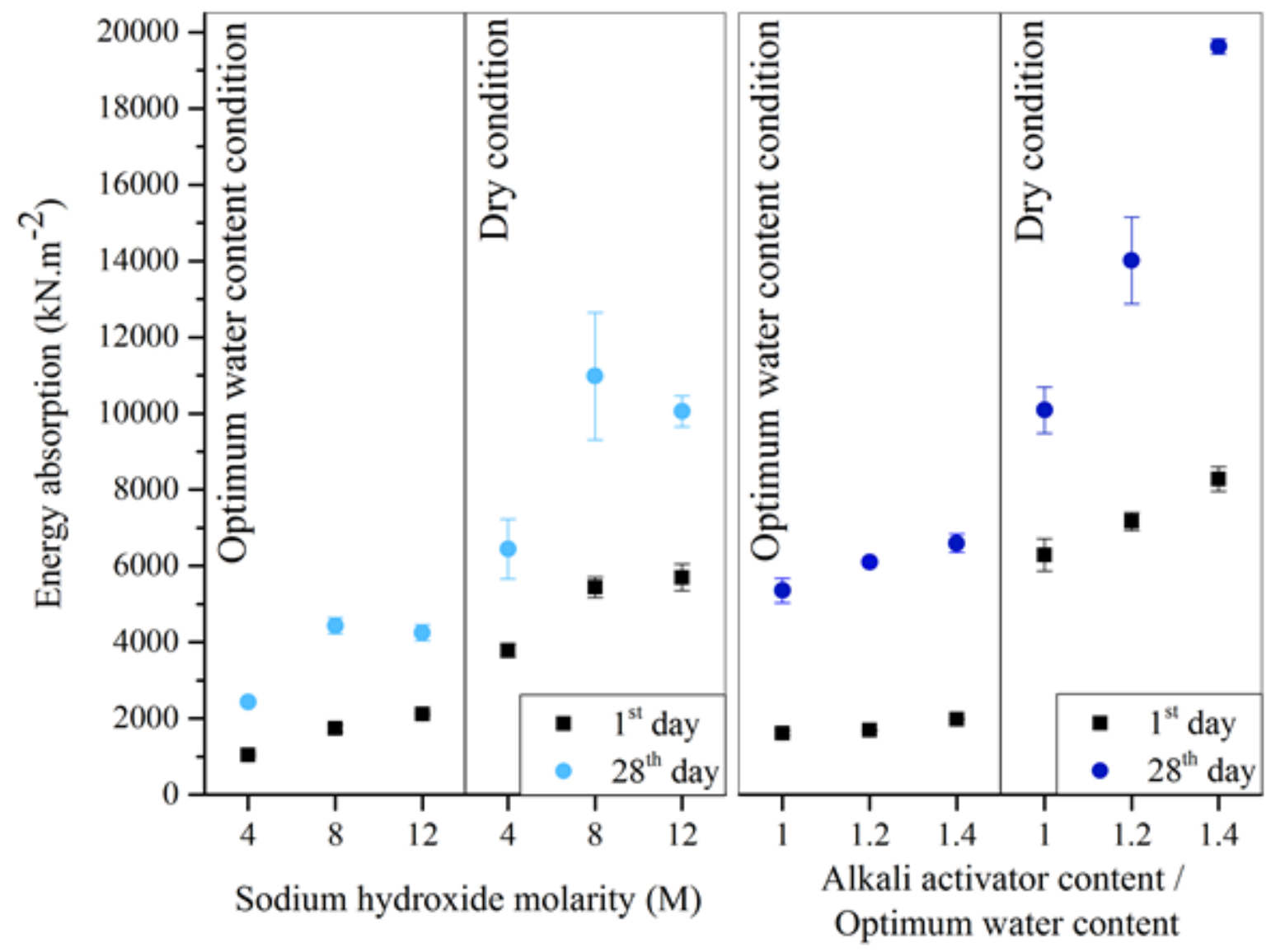

Fig 11. Energy absorption of stabilized soils using geopolymer at optimum water content and dry conditions with different alkali activator content and concentration at different ages.

\section{Discussion}

Dissolution and precipitation reactions of silicates, aluminates and calcium sources and hence the stable equilibrium phase assemblages of the oxide compositions are mainly depending on the $\mathrm{pH}$ of the medium and oxide concentration. Figure 12 shows that the $\mathrm{pH}$ of the geopolymer treated soil is about 11.5 to 12.5 which, depending on the activator concentration and binder content. A higher mechanical strength was obtained at higher $\mathrm{pH}$ where alkali activator concentration is higher $[\underline{43}$, 44]. This is due to the predominance of smaller chain oligomers and monomeric silicate available to react with soluble aluminum in the presence of higher concentration of hydrogen ions during 
dissolution and hydrolysis stages. This mechanism can be incorporated by calcium precursors available in VA [45]. Therefore, higher binder gel is produced. Possible dissolution (equations 1 and 2) and precipitation (equations 3 and 4) reactions occur during setting and hardening processes of high calcium based systems are [46]:

$$
\begin{aligned}
& \mathrm{CaSO}_{4}, \mathrm{CaO} \stackrel{\mathrm{H}_{2} \mathrm{O}}{\longrightarrow} \mathrm{Ca}^{+2}+\mathrm{SO}_{4}^{-2}+\mathrm{OH}^{-} \\
& \mathrm{SiO}_{2}+\mathrm{Al}_{2} \mathrm{O}_{3} \stackrel{\mathrm{OH}^{-}}{\longrightarrow} \mathrm{SiO}_{2}(\mathrm{OH})_{2}^{2-}{ }_{\text {or }} \mathrm{SiO}(\mathrm{OH})_{3}^{-1}+\mathrm{Al}(\mathrm{OH})_{4}^{-} \\
& \mathrm{Ca}^{+2}+\mathrm{SiO}_{2}(\mathrm{OH})_{2}^{2-} \mathrm{SiO}(\mathrm{OH})_{3}^{-1}+\mathrm{Al}(\mathrm{OH})_{4}^{-} \longrightarrow \mathrm{CASH}_{\text {gel }} \\
& \mathrm{Na}^{+}+\mathrm{SiO}_{2}(\mathrm{OH})_{2}^{2-}{ }_{\text {or }} \mathrm{SiO}(\mathrm{OH})_{3}^{-1}+\mathrm{Al}(\mathrm{OH})_{4}^{-} \longrightarrow \mathrm{NASH}_{g e l}
\end{aligned}
$$

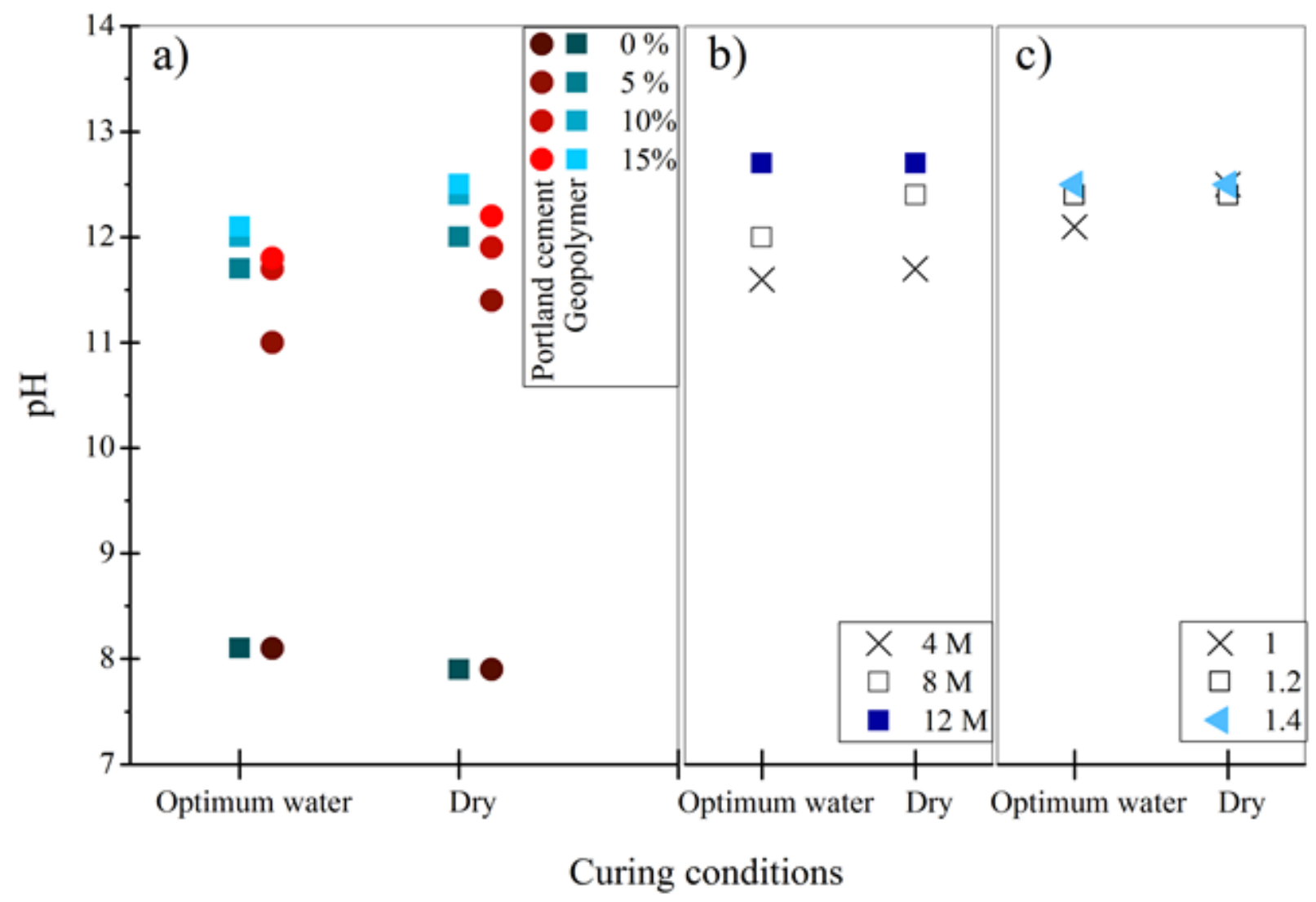


Figure 12. $\mathrm{pH}$ values of stabilized soils using geopolymer and $\mathrm{OPC}$ at optimum water content and dry condition with different binder content at $28^{\text {th }}$ day of curing.

Similarly, upon the addition of water to OPC, each of the compounds undergoes hydration. However, mainly calcium silicates contribute in further mechanical strength development. In particular, tricalcium silicate initiates to release calcium ions, hydroxide ions. This reaction continuous till the system gets saturated and followed by crystallization of calcium hydroxide and formation of calcium silicate hydrate, equation 5. Simultaneously, dicalcium silicate reacts with water in a similar manner but with a slower rate, equation 6 .

$$
\begin{aligned}
& \mathrm{Ca}_{3} \mathrm{SiO}_{5} \stackrel{\mathrm{H}_{2} \mathrm{O}}{\longrightarrow} \mathrm{CSH}+\mathrm{Ca}(\mathrm{OH})_{2} \\
& \mathrm{Ca}_{2} \mathrm{SiO}_{4} \stackrel{\mathrm{H}_{2} \mathrm{O}}{\longrightarrow} \mathrm{CSH}+\mathrm{Ca}(\mathrm{OH})_{2}
\end{aligned}
$$

This gel formation can be explored through the evaluation of $\mathrm{pH}$ value. As observed in Figure 12, the $\mathrm{pH}$ value rises in the range of 11 to 12.1 when the OPC concentrations increased from 5 to 15 w.t. \%. However, it was reported that the $\mathrm{pH}$ value increases significantly at lower cement content, but it stabled at the cement content of about 20 and above [47, 48].

The formation of the calcium hydroxide and calcium silicate hydrate crystals provide "seeds" upon which more calcium silicate hydrate can form. The calcium silicate hydrate crystals grow thicker, making it more difficult for water molecules to reach the unhydrated tricalcium silicate. Therefore, the strength development is reduced over time [49]. This is compounded when the water is not sufficient in the system or evaporated because of exothermic reactions and curing at hot and dry environments [50-52]. This loses the functionality of OPC stabilization at torrid zones. 


\section{Conclusions}

This study compares the potential of geopolymer as an alternative environmental friendly clayey soil stabilizer to the conventional OPC in dry (DC) and wet (OC) curing conditions. The compressive strength of the untreated clayey soil specimens could be increased from 0.2 to $4 \mathrm{MPa}$ and 2 to $12 \mathrm{MPa}$ at the $\mathrm{OC}$ and DC conditions, respectively, when the soil partially replaced with 15 w.t. $\%$ of the binders. This increase is significantly depending on curing humidity and temperature. The VA-geopolymer stabilized soil indicated $200 \%$ improvement in compressive strength compares with the corresponding OPC specimens at the DC condition. While, OPC stabilized soil was superb at OC and shows $33 \%$ higher strength compare to the geopolymer specimens. Furthermore, high energy absorption in all the geopolymer specimens shows the ductile behavior of this material compare with OPC.

In addition to the curing condition, the increase in molarity of the sodium hydroxide from 4 to 12 $\mathrm{M}$ resulted in higher dissolution of aluminosilicate precursors and a consequent higher binder gel production. This leads to a higher mechanical strength (up to 50\%) of the geopolymer specimens at both OC and DC. Furthermore, the increase in alkali activator content/optimum water content from 1 to 1.4 improves the DC compressive strength up to about $70 \%$ and $130 \%$ at 1 st and 28 th day, respectively. Whereas, the increase in alkali activator was ineffective at the OC, which is associated with the dilution of alkali activator at the wet condition.

\section{Conflict of interest}

The authors declare no conflict of interest. 


\section{References}

[1] Y. Yi, L. Gu, S. Liu, Microstructural and mechanical properties of marine soft clay stabilized by lime-activated ground granulated blastfurnace slag, Applied Clay Science 103 (2015) 71-76.

[2] J.-H. Yin, W.-H. Zhou, Influence of grouting pressure and overburden stress on the interface resistance of a soil nail, Journal of Geotechnical and Geoenvironmental Engineering 135(9) (2009) 1198-1208.

[3] G.A. Lorenzo, D.T. Bergado, Fundamental characteristics of cement-admixed clay in deep mixing, Journal of materials in civil engineering 18(2) (2006) 161-174.

[4] A. Bosoaga, O. Masek, J.E. Oakey, CO2 Capture Technologies for Cement Industry, Energy Procedia 1(1) (2009) 133-140.

[5] H. Fatehi, S.M. Abtahi, H. Hashemolhosseini, S.M. Hejazi, A novel study on using protein based biopolymers in soil strengthening, Construction and Building Materials 167 (2018) 813-821. [6] A. Mosallanejad, H. Taghvaei, S.M. Mirsoleimani-azizi, A. Mohammadi, M.R. Rahimpour, Plasma upgrading of 4methylanisole: A novel approach for hydrodeoxygenation of bio oil without using a hydrogen source, Chemical Engineering Research and Design 121 (2017) 113-124.

[7] A.H. Bushlaibi, A.M. Alshamsi, Efficiency of curing on partially exposed high-strength concrete in hot climate, Cement and concrete research 32(6) (2002) 949-953.

[8] S. Pourakbar, A. Asadi, B.B.K. Huat, M.H. Fasihnikoutalab, Stabilization of clayey soil using ultrafine palm oil fuel ash (POFA) and cement, Transportation Geotechnics 3 (2015) 24-35.

[9] P. Hughes, S. Glendinning, Deep dry mix ground improvement of a soft peaty clay using blast furnace slag and red gypsum, Quarterly Journal of Engineering Geology and Hydrogeology 37(3) (2004) 205-216.

[10] C. Shi, D. Roy, P. Krivenko, Alkali-activated cements and concretes, CRC press2003.

[11] Y. Yi, C. Li, S. Liu, Alkali-activated ground-granulated blast furnace slag for stabilization of marine soft clay, Journal of materials in civil engineering 27(4) (2014) 04014146.

[12] S. Song, D. Sohn, H. Jennings, T. Mason, Hydration of alkali-activated ground granulated blast furnace slag, Journal of Materials Science 35(1) (2000) 249-257.

[13] N. Ranjbar, M. Mehrali, M.R. Maheri, M. Mehrali, Hot-pressed geopolymer, Cement and Concrete Research 100 (2017) 14-22.

[14] C. Phetchuay, S. Horpibulsuk, A. Arulrajah, C. Suksiripattanapong, A. Udomchai, Strength development in soft marine clay stabilized by fly ash and calcium carbide residue based geopolymer, Applied Clay Science 127 (2016) 134-142.

[15] B. Singhi, A.I. Laskar, M.A. Ahmed, Mechanical Behavior and Sulfate Resistance of Alkali Activated Stabilized Clayey Soil, Geotechnical and Geological Engineering 35(5) (2017) 19071920.

[16] B. Singhi, A.I. Laskar, M.A. Ahmed, Investigation on Soil-Geopolymer with Slag, Fly Ash and Their Blending, Arabian Journal for Science and Engineering 41(2) (2016) 393-400.

[17] M. Zhang, H. Guo, T. El-Korchi, G. Zhang, M. Tao, Experimental feasibility study of geopolymer as the next-generation soil stabilizer, Construction and Building Materials 47 (2013) 1468-1478.

[18] P. Sargent, P.N. Hughes, M. Rouainia, M.L. White, The use of alkali activated waste binders in enhancing the mechanical properties and durability of soft alluvial soils, Engineering geology 152(1) (2013) 96-108. 
[19] Y.-J. Du, B.-W. Yu, K. Liu, N.-J. Jiang, M.D. Liu, Physical, hydraulic, and mechanical properties of clayey soil stabilized by lightweight alkali-activated slag geopolymer, Journal of Materials in Civil Engineering 29(2) (2016) 04016217.

[20] S. Rios, N. Cristelo, A. Viana da Fonseca, C. Ferreira, Structural performance of alkaliactivated soil ash versus soil cement, Journal of Materials in Civil Engineering 28(2) (2015) 04015125.

[21] N. Cristelo, S. Glendinning, L. Fernandes, A.T. Pinto, Effects of alkaline-activated fly ash and Portland cement on soft soil stabilisation, Acta Geotechnica 8(4) (2013) 395-405.

[22] H.Y. Leong, D.E.L. Ong, J.G. Sanjayan, A. Nazari, Strength Development of Soil-Fly Ash Geopolymer: Assessment of Soil, Fly Ash, Alkali Activators, and Water, Journal of Materials in Civil Engineering 30(8) (2018) 04018171.

[23] C. Phetchuay, S. Horpibulsuk, C. Suksiripattanapong, A. Chinkulkijniwat, A. Arulrajah, M.M. Disfani, Calcium carbide residue: Alkaline activator for clay-fly ash geopolymer, Construction and Building Materials 69 (2014) 285-294.

[24] S. Pourakbar, B.B. Huat, A. Asadi, M.H. Fasihnikoutalab, Model study of alkali-activated waste binder for soil stabilization, International Journal of Geosynthetics and Ground Engineering 2(4) (2016) 35.

[25] S. Rios, C. Ramos, A. Viana da Fonseca, N. Cruz, C. Rodrigues, Mechanical and durability properties of a soil stabilised with an alkali-activated cement, European Journal of Environmental and Civil Engineering (2017) 1-23.

[26] N. Cristelo, S. Glendinning, T. Miranda, D. Oliveira, R. Silva, Soil stabilisation using alkaline activation of fly ash for self compacting rammed earth construction, Construction and Building Materials 36 (2012) 727-735.

[27] N. Ranjbar, M. Mehrali, M. Mehrali, U.J. Alengaram, M.Z. Jumaat, High tensile strength fly ash based geopolymer composite using copper coated micro steel fiber, Construction and building materials 112 (2016) 629-638.

[28] N. Ranjbar, C. Kuenzel, Influence of preheating of fly ash precursors to produce geopolymers, Journal of the American Ceramic Society (2017).

[29] C. Kuenzel, L.J. Vandeperre, S. Donatello, A.R. Boccaccini, C. Cheeseman, Ambient temperature drying shrinkage and cracking in metakaolin-based geopolymers, Journal of the American Ceramic Society 95(10) (2012) 3270-3277.

[30] N. Ranjbar, M. Mehrali, U.J. Alengaram, H.S.C. Metselaar, M.Z. Jumaat, Compressive strength and microstructural analysis of fly ash/palm oil fuel ash based geopolymer mortar under elevated temperatures, Construction and building materials 65 (2014) 114-121.

[31] Z. Zuhua, Y. Xiao, Z. Huajun, C. Yue, Role of water in the synthesis of calcined kaolin-based geopolymer, Applied Clay Science 43(2) (2009) 218-223.

[32] H. Xu, J.S. van Deventer, The effect of alkali metals on the formation of geopolymeric gels from alkali-feldspars, Colloids and Surfaces A: Physicochemical and Engineering Aspects 216(1) (2003) 27-44.

[33] N. Ranjbar, A. Kashefi, M.R. Maheri, Hot-pressed geopolymer: Dual effects of heat and curing time, Cement and Concrete Composites 86 (2018) 1-8.

[34] N. Hataf, P. Ghadir, N. Ranjbar, Investigation of soil stabilization using chitosan biopolymer, Journal of Cleaner Production 170 (2018) 1493-1500.

[35] I. Chang, A.K. Prasidhi, J. Im, G.-C. Cho, Soil strengthening using thermo-gelation biopolymers, Construction and Building Materials 77 (2015) 430-438. 
[36] S. Kolias, V. Kasselouri-Rigopoulou, A. Karahalios, Stabilisation of clayey soils with high calcium fly ash and cement, Cement and Concrete Composites 27(2) (2005) 301-313.

[37] P.N. Lemougna, K.J.D. MacKenzie, U.F.C. Melo, Synthesis and thermal properties of inorganic polymers (geopolymers) for structural and refractory applications from volcanic ash, Ceramics International 37(8) (2011) 3011-3018.

[38] D. Panias, I.P. Giannopoulou, T. Perraki, Effect of synthesis parameters on the mechanical properties of fly ash-based geopolymers, Colloids and Surfaces A: Physicochemical and Engineering Aspects 301(1) (2007) 246-254.

[39] P. Chindaprasirt, W. Chalee, Effect of sodium hydroxide concentration on chloride penetration and steel corrosion of fly ash-based geopolymer concrete under marine site, Construction and Building Materials 63(Supplement C) (2014) 303-310.

[40] C. Kuenzel, T. Neville, S. Donatello, L. Vandeperre, A. Boccaccini, C. Cheeseman, Influence of metakaolin characteristics on the mechanical properties of geopolymers, Appl. Clay Sci. 83 (2013) 308-314.

[41] X. Guo, H. Shi, W.A. Dick, Compressive strength and microstructural characteristics of class C fly ash geopolymer, Cement and Concrete Composites 32(2) (2010) 142-147.

[42] N. Ranjbar, A. Behnia, H.K. Chai, U.J. Alengaram, M.Z. Jumaat, Fracture evaluation of multilayered precast reinforced geopolymer-concrete composite beams by incorporating acoustic emission into mechanical analysis, Construction and Building Materials 127 (2016) 274-283.

[43] J.W. Phair, J.S.J. Van Deventer, Effect of the silicate activator $\mathrm{pH}$ on the microstructural characteristics of waste-based geopolymers, International Journal of Mineral Processing 66(1) (2002) 121-143.

[44] D. Khale, R. Chaudhary, Mechanism of geopolymerization and factors influencing its development: a review, Journal of Materials Science 42(3) (2007) 729-746.

[45] J.W. Phair, J.S.J. Van Deventer, Effect of silicate activator pH on the leaching and material characteristics of waste-based inorganic polymers, Minerals Engineering 14(3) (2001) 289-304.

[46] P. Chindaprasirt, P. De Silva, K. Sagoe-Crentsil, S. Hanjitsuwan, Effect of SiO2 and Al2O3 on the setting and hardening of high calcium fly ash-based geopolymer systems, Journal of Materials Science 47(12) (2012) 4876-4883.

[47] S. Chew, A. Kamruzzaman, F. Lee, Physicochemical and engineering behavior of cement treated clays, Journal of geotechnical and geoenvironmental engineering 130(7) (2004) 696-706.

[48] G.A. Miller, S. Azad, Influence of soil type on stabilization with cement kiln dust, Construction and Building Materials 14(2) (2000) 89-97.

[49] G.C. Bye, Portland cement: composition, production and properties, Thomas Telford1999.

[50] M. Ghrici, S. Kenai, E. Meziane, Mechanical and durability properties of cement mortar with Algerian natural pozzolana, Journal of Materials Science 41(21) (2006) 6965-6972.

[51] S.H. Alsayed, M.A. Amjad, Effect of curing conditions on strength, porosity, absorptivity, ans shrinkage of concrete in hot and dry climate, Cement and Concrete Research 24(7) (1994) 13901398.

[52] A. Kriker, G. Debicki, A. Bali, M.M. Khenfer, M. Chabannet, Mechanical properties of date palm fibres and concrete reinforced with date palm fibres in hot-dry climate, Cement and Concrete Composites 27(5) (2005) 554-564. 